\title{
A CELLULOID CAPSULE FOR MEASURING VENOUS PRESSURES
}

\author{
By A. KROGH, A. H. TURNER ${ }^{1}$ AND E. M. LANDIS 2
}

(From the Laboratory of Zoophysiology, University of Copenhagen, Copenhagen, Denmark)

(Received for publication November 3, 1931)

The methods of determining human venous pressure directly by venous puncture and indirectly in various ways have been reviewed by Eyster, 1926, 1929. Among the indirect methods that of applying a capsule to a superficial vein has been most used. The air within the capsule is raised to a pressure sufficient to collapse the vein, a pressure therefore estimated approximately equal to the blood pressure within the vein. The capsules used have been of two kinds, (1) a capsule held by hand against the skin with the help of a glycerine coating, with the vein seen either through a transparent membrane (Carrier and Rehberg, 1923) or through a hole in a thin rubber membrane (Eyster, 1929); (2) a glass capsule with no membrane but attached to the skin around its periphery by collodion (Hooker, 1916). Though these capsules have been very useful, difficulties have been recognized in making accurate determinations. At best it is not easy to be sure of the exact end-point and any membrane through which the vein must be observed lessens visibility. In an attempt to measure the high venous pressures in the feet of standing subjects it was found impossible to hold either type of membrane capsule against the skin with sufficient steadiness to secure trustworthy figures. An attached glass capsule, however, is too rigid to fit veins varying in size and arrangement. The skin around and inside such a capsule, also, is deformed conspicuously if a high pressure must be used.

The description of a new capsule and a counterweighting clamp which obviate these difficulties is the purpose of this paper. The essential features of construction and use are these. The capsule is made of celluloid which permits the cutting of notches to fit any vein. Its construction is so simple that a dozen may be made in an hour. A considerable length of vein is under observation. By a clamp for counterweighting there is freedom from the skin deformation incident to any attached capsule at high pressures. Comparable serial readings are possible through any length of time.

${ }^{1}$ Sarah Berliner Fellow of the American Association of University Women, 1930-1931.

${ }^{2}$ Fellow of the John Simon Guggenheim Memorial Foundation. 
The capsule and its clamp are shown in Figure 1. In making the capsule, $A$, a ring $1 \mathrm{~cm}$. wide is cut from celluloid tubing ${ }^{3} 2.5 \mathrm{~cm}$. in diameter with a wall thickness of $1 \mathrm{~mm}$. To this a cover of sheet celluloid, $B$, is cemented by acetone. The shape of the capsule is made conveniently oval by compressing the ring as the cover is cemented on. A tube $3 \mathrm{~mm}$. in diameter is cemented into a hole bored in the rim, for

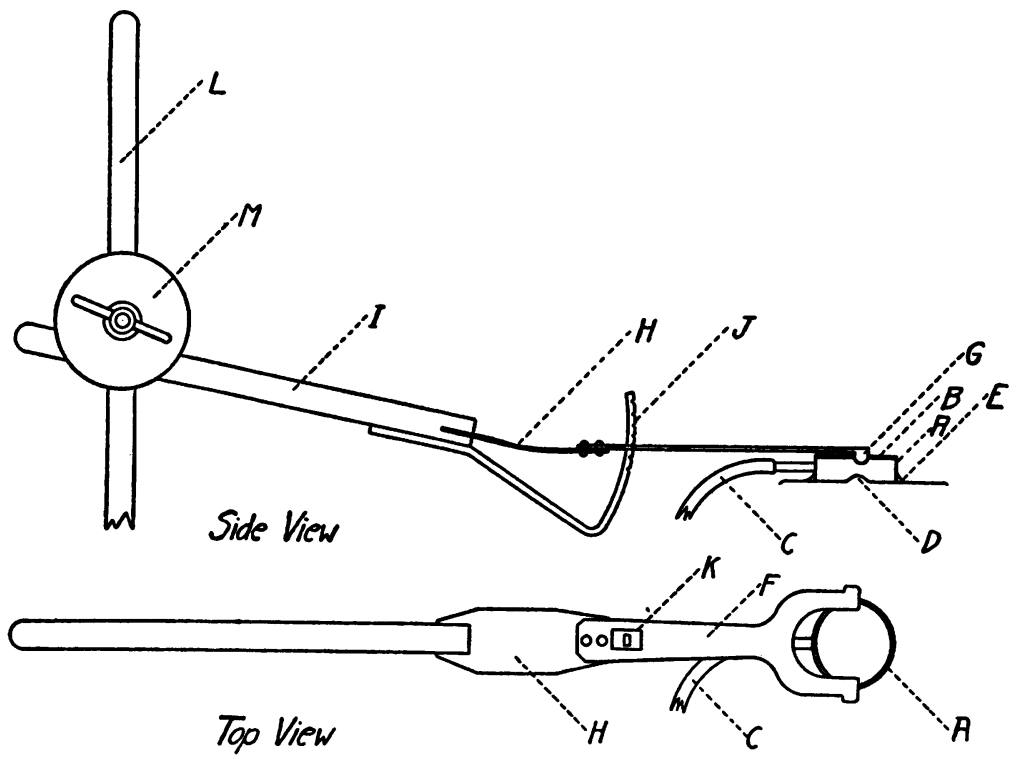

Fig. 1. Capsule and Counterweighting Clamp Used for Determination of Venous Pressure

For description, see text.

communication with the pressure apparatus through the rubber tube, $C$. While the capsule is drying it is so placed as to be freely open to the air since acetone vapor lessens the transparency of the celluloid top. The advantages of celluloid as compared with glass are not only its unbreakability and the easy manufacture of new capsules but the fact that notches, $D$, can be cut in it to fit any conformation of veins.

\section{Observation of low venous pressures}

For the true reading of venous pressures the vein chosen must be separated from a firm underlying bony support by as little intervening tissue as possible. The capsule was so placed that the best portion of the vein chosen for observation was in the middle of the inclosed area. The capsule was cemented to the skin by a rather thick solution of collodion.

${ }^{3}$ Celluloid tubing of different sizes can be procured from Deutsche Celloidfabrik, Eulenburg, Sachsen, Germany. Other laboratory uses for these celluloid products are suggested by Krogh and Lange, 1930. 
For low pressures a single coat and a drying time of ten minutes were found sufficient. The capsule was easily held in place during drying by the clamp to be described below. For pressures up to 30 or $40 \mathrm{~cm}$. of water a water manometer can be used. Pressure was applied by a thickwalled rubber bulb without valves. Compression was well-controlled by a screw clamp between the jaws of which the bulb was supported. Removal of the capsule at the end of the observations was effected by the aid of ether and alcohol which, however, was not allowed to touch the transparent top of the capsule.

The end-point used in our determinations was not the mere collapse of the vein for it was difficult to tell when this was complete. When the skin was sufficiently transparent the end-point was taken at the level where the thin blue line marking a very small amount of blood flowing in the flattened vein first reappeared after it had been driven out by a somewhat higher pressure. By a slight movement of the compressing screw up and down or, more effectively, by sharp pinches on the tube leading to the capsule small quick changes in pressure of about 1 to 1.5 $\mathrm{cm}$. were made. As the vein was watched during this manoeuvre, usually with oblique lighting, the disappearance and reappearance of this last thin stream of blood could be determined with considerable accuracy. If the tissues were less transparent the to and fro movement of the wall of the vein as distinct from the movement of the whole area of skin under the capsule was used as a criterion.

The validity of these determinations of relatively low pressure was tested by putting various pressures on the upper arm through an armlet with a rubber bag of ample size, $50 \times 15 \mathrm{~cm}$. Such an application of pressure is well known to raise the pressure of the blood in the veins below the armlet to a height approximately equal to the pressure applied. In a long series of experiments in which it was necessary to know venous pressures (Krogh, Landis and Turner, 1932) armlet pressures from 15 to $30 \mathrm{~cm}$. of water were checked many times and venous pressures in the hand veins found to correspond with great fidelity. The variation from the armlet pressure was rarely more than $1 \mathrm{~cm}$.

\section{Observations of high venous pressures}

For determining high venous pressures such as those found in the veins of the feet during sitting or standing some modifications of procedure were made. In cementing on the capsule it was necessary to use two or three coats of collodion and to allow a much longer drying time, fully a half hour. A mercury manometer was used in connection with a large rubber bulb which was compressed by a screw clamp as before. The same technic for determining the end-point was used as for low pressures though the zone of error was probably wider.

When pressure within the capsule is $30 \mathrm{~mm}$. $\mathrm{Hg}$ or more there is usually obvious distortion of the skin within and around the capsule, 
though to a degree varying in different subjects and situations according to the looseness of the skin and underlying tissues. This cupping of the skin tends to facilitate the passage of blood under the capsule and thus to necessitate for obliteration of the flow a capsular pressure higher than the true venous pressure. To prevent error due to this cause the clamp shown in top and side views in Figure 1 was devised. This was applied to the capsule with a pressure approximately equal to the expected venous pressure thus holding the capsule down and preventing skin deformation. Blood flow was not affected because of the notches in the capsule. The clamp was made and graduated thus. A brass section, $F$, was made with jaws of a proper size to fit the capsule and with small vertical pieces, $G$, at the ends of the jaws to prevent lateral movement on the capsule. Other small vertical pieces at right angles to $G$, not shown in the figure, made the line of pressure on the capsule precise. The section $F$ was securely soldered and fastened by small bolts to a thin steel spring, $H$, which in turn was soldered fast into the handle, $I$. The pressure of the clamp upon the capsule was obviously dependent upon the degree to which the spring $H$ was bent. This bending was measured by a graduated brass arc, $J$, which was attached to the handle as shown and which passed through a hole, $K$, in the brass section $F$. The clamp was borne by a stand, $L$, with a heavy base and its adjustment was easily controlled by a universal clamp, $M$. The total length of the clamp was $27 \mathrm{~cm}$.

In graduating the clamp its position was inverted and weights from 100 to 600 grams, covering the range of probable need, were hung from the brass jaws along the line where pressure was usually exerted on the capsule. The position of the spring for each additional hundred grams of weight was indicated upon the brass arc. To determine the weight to be placed upon the capsule the probable venous pressure is estimated from the comparative levels of the vein in question and the heart, and such a weighting from the spring is provided as will counterbalance the necessary pressure within the capsule and maintain its natural relation to the skin. Suppose, for example, that the vein is $60 \mathrm{~cm}$. below the heart, the venous pressure then may not vary greatly from this, let us say 60 to $65 \mathrm{~cm}$. water pressure ( 44 to $48 \mathrm{~mm}$. $\mathrm{Hg}$ ). The surface of an oval capsule with an average diameter of $23 \mathrm{~mm}$. will be slightly less than $4.15 \mathrm{sq} . \mathrm{cm}$. The weighting needed in this case to prevent deformation of the skin will be $62.5 \times 4.15$ or about 260 grams. From the size of the scale on the clamp it is possible to apply pressures with an error of about 10 grams, a degree of accuracy entirely adequate. For a few pressures suitable weightings for a capsule of the size mentioned would be as follows.

$20 \mathrm{~mm} . \mathrm{Hg}$ venous pressure, 110 grams

$40 \mathrm{~mm}$. $\mathrm{Hg}$ venous pressure, 225 grams

$60 \mathrm{~mm}$. $\mathrm{Hg}$ venous pressure, 335 grams

$80 \mathrm{~mm}$. $\mathrm{Hg}$ venous pressure, 450 grams 
The validity of the determinations at the higher pressures was tested by putting the pressures indicated in Table 1 on the upper arm by an

TABLE 1

Test for importance of counterweighting with use of celluloid capsule at high venous pressures. For discussion, see text

\begin{tabular}{|c|c|c|}
\hline Armlet pressure & Counterweight by clamp & Venous pressure as determined \\
\hline 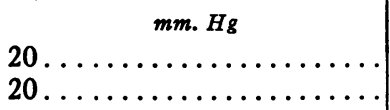 & $\begin{array}{c}\text { grams } \\
120 \\
0\end{array}$ & $\begin{array}{l}m m . H g \\
20 \\
20\end{array}$ \\
\hline 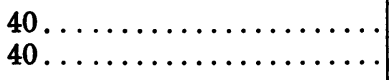 & $\begin{array}{r}240 \\
0\end{array}$ & $\begin{array}{l}39,41 \\
43,40\end{array}$ \\
\hline $\begin{array}{l}60 \ldots \ldots \ldots \ldots \ldots \ldots \ldots \ldots \ldots \\
60 \ldots \ldots \ldots \ldots \ldots \ldots\end{array}$ & $\begin{array}{r}360 \\
0\end{array}$ & $\begin{array}{l}59,60 \\
62,66\end{array}$ \\
\hline $\begin{array}{l}80 \ldots \ldots \ldots \ldots \ldots \ldots \ldots \ldots \ldots \ldots \\
80 \ldots \ldots \ldots \ldots \ldots \ldots \ldots\end{array}$ & $\begin{array}{r}480 \\
0\end{array}$ & $\begin{array}{c}80 \\
100,94\end{array}$ \\
\hline
\end{tabular}

armlet. The hand vein to be observed was kept at heart height. The pressure was applied in each case five minutes before the determination of venous pressure was made in order to give venous pressure time to come into equilibrium with armlet pressure. Counterweighting was employed as indicated, calculated from the size of the capsule and the expected venous pressure. After a determination was made at each pressure and while the intracapsular pressure remained on, the weighting clamp was gently removed. Cupping of the skin was seen as the pressure of the clamp was taken off. The vein was watched carefully for the entrance or lack of entrance of blood. If blood was seen to enter the vein, additional pressure was applied to collapse the vein again completely. In other words a measurement was made of the error which would have occurred had there been no counterweighting in the first determination. The pressures given in the table are single determinations, not averages, and are all from one subject. It will be seen that for $20 \mathrm{~mm}$. $\mathrm{Hg}$ there was no need of counterweighting; for $40 \mathrm{~mm}$. it perhaps was not required though it was clearly needed for another subject at this pressure; but for the higher pressures of 60 and $80 \mathrm{~mm}$. $\mathrm{Hg}$ there was a large and variable error without the counterweight. The importance of counterweighting for the accurate determination of the higher venous pressures is thus clearly seen. It is safer to use it as soon as skin distortion is apparent.

Fogging of the capsule is a frequent difficulty with any attached capsule when observations extend over a considerable period. It is due to the condensation of water vapor on the under side of the top of the capsule and was avoided by keeping the capsule warm. A light pad of cotton wool applied between determinations was usually sufficient but in 
more persistent fogging a silver disc heated in a flame to a suitable temperature was laid gently upon the capsule until the fog was dissipated.

\section{SUMMARY}

A celluloid capsule for the determination of venous pressures is described. This is very easily made and notches can be cut so that it will fit any arrangement of veins. It is cemented to the skin with collodion. When with high venous pressures the necessarily high intracapsular pressure would cause distortion of the skin and erroneous readings, the error can be avoided by the use of a counterweighting clamp, also described. Such a counterweight is usually needed for the measurement of venous pressures above $30 \mathrm{~cm}$. water pressure.

\section{BIBLIOGRAPHY}

Carrier, E. B., and Rehberg, P. B., Skandinav. Arch. f. Physiol., 1923, xliv, 20. Capillary and Venous Pressure in Man.

Eyster, J. A. E., Physiol. Rev., 1926, vi, 281. Venous Pressure and its Clinical Applications.

Eyster, J. A. E., The Clinical Aspects of Venous Pressure. The Macmillan Company, New York, 1929.

Hooker, D. R., Am. J. Physiol., 1916, xl, 43. The Influence of Age upon the Venous Blood Pressure in Man.

Krogh, A., and Lange, E., Biochem. Ztschr., 1930, ccxxi, 489. Über die Anwendung von Celluloid, besonders Celluloidröhren im Laboratorium.

Krogh, A., Landis, E. M., and Turner, A. H., J. Clin. Invest., 1932, xi, 63. The Movement of Fluid through the Human Capillary Wall in Relation to Venous Pressure and to the Colloid Osmotic Pressure of the Blood. 